\title{
La inducción al trabajo interdisciplinario a partir de la imagen en el arte y la literatura como herramienta para propiciar la problematización de la transdisciplinariedad
}

The induction to interdisciplinary work from the image in art and literature
\[ \text { as a tool to promote the problematization of transdisciplinarity } \]

Indução ao trabalho interdisciplinar a partir da imagem na arte e na literatura como ferramenta para promover a problematização da transdisciplinaridade

Lourdes Yunuen Martínez Puente Universidad Autónoma de Querétaro, México

lourdes.yunuen.martinez@uaq.mx https://orcid.org/0000-0001-8643-2039

\section{Resumen}

En este artículo se reflexiona en torno al trabajo interdisciplinario de las artes y la literatura como propuesta ante las problemáticas que presenta la educación superior en la actualidad y para hacer visible la importancia de la transdisciplina en este contexto. Esta reflexión también está encaminada a aportar elementos teóricos y prácticos como material académico de la materia Fundamentos teóricos de artes visuales, que forma parte del curso propedéutico de la maestría en Estudios Interdisciplinarios en Arte y Humanidades de la Universidad Autónoma de Querétaro. El análisis se realiza a partir de cinco apartados: el concepto de figura ${ }^{1}$ a partir de la propuesta de Raúl Dorra, un enfoque por competencias

\footnotetext{
${ }^{1}$ En su libro La retórica como arte de la mirada (2002), Raúl Dorra concibe el discurso literario o poético como "un cuerpo que hace figura". El cuerpo/figura deviene espectáculo para la mirada. La propuesta de Dorra será el medio de aproximación para reflexionar sobre ese cuerpo que hace figura en obras plásticas, literarias, en incluso, investigativas. Para el escritor argentino, la construcción de la idea occidental de
} 


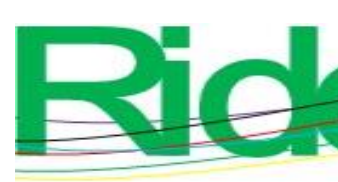

Revista Iberoamericana para la Investigación y el Desarrollo Educativo ISSN 2007 - 7467

cooperativas, el concepto de racionalidad, el método hermenéutico crítico y la concepción de interrelaciones dialogales y de interacciones disciplinares. Por último, se muestran los resultados en torno a la problemática planteada a partir de su caracterización y posible pertinencia.

Palabras clave: conexión, diálogo, figura y educación superior.

\section{Abstract}

This paper considers the interdisciplinary work of plastic arts and literature, as a proposal to deal with the contemporary problems presented in higher education and to make visible the importance of transdiscipline in this context. This reflection is also aimed at providing theoretical and practical elements as academic material of the subject "Fundamentos teóricos de artes visuales" which is part of the preparatory course of the "Maestría en estudios interdisciplinarios en arte y humanidades" at the "Universidad Autónoma de Querétaro". The analysis has five sections: the concept of figure based on Raúl Dorra's proposal, a cooperative competition approach, the concept of rationality, the critical hermeneutical method and the conception of dialogical interrelationships and disciplinary interactions. Finally, results are shown around the problem raised, based on its characterization and possible relevance.

Keywords: connection, dialogue, figure and higher education.

\section{Resumo}

Este artigo reflete sobre o trabalho interdisciplinar das artes e da literatura como uma proposta diante dos problemas que a educação superior apresenta hoje e para tornar visível a importância da transdisciplina neste contexto. Esta reflexão visa também fornecer elementos teóricos e práticos como material acadêmico da disciplina Fundamentos teóricos

discurso, desde su designación como "figura del discurso", establece una relación de analogía con el cuerpo. Mas no se trata de cualquier cuerpo, sino un cuerpo humano modelado por una disciplina como la gimnasia o la danza. Es en este sentido que las palabras nos remiten a la tensión de un cuerpo que se ofrece como espectáculo y de esta manera "hace figura": "La figura sería originalmente, entonces, la que hace el gimnasta o el bailarín cuando, frente a un público también educado por el arte, tensa su cuerpo y lo ofrece a la mirada convertido en espectáculo. Así, el cuerpo hace figura en el momento en que trasciende su densidad somática y adquiere la propiedad de ser pura forma" (Dorra, 2002, p. 18). 


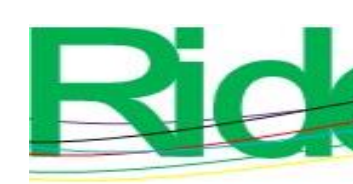

Revista Iberoamericana para la
Investigación y el Desarrollo Educativo
ISSN $2007-7467$

das artes visuais, que faz parte do curso preparatório para o mestrado em Estudos Interdisciplinares em Arte e Humanidades da Universidade Autônoma de Querétaro. A análise é realizada a partir de cinco seções: o conceito de figura a partir da proposta de Raúl Dorra, uma abordagem por competências cooperativas, o conceito de racionalidade, o método hermenêutico crítico e a concepção de inter-relações dialógicas e interações disciplinares. Por fim, são apresentados os resultados relativos ao problema levantado a partir de sua caracterização e possível relevância.

Palavras-chave: conexão, diálogo, figura e educação superior.

Fecha Recepción: Octubre 2020

Fecha Aceptación: Marzo 2021

\section{Introducción}

El objetivo de estas reflexiones investigativas - en el contexto de la educación superior (en especial la artística) — es promover el desarrollo de la capacidad para hacer figuras (creativo-investigativas) a partir del diálogo en torno a la imagen en el arte y la literatura. Este artículo, por ende, es el resultado de una investigación de carácter teórico orientada a realizar reflexiones propositivas a favor de prácticas educativas. Para ello, se asocian textos y documentos en torno a un enfoque por competencias, el concepto de racionalidad y el método para examinar sus problemáticas, y a partir del arte y la literatura hacer un análisis teórico especulativo desde significados antitéticos. Por otro lado, se propone una inducción al trabajo interdisciplinario (arte y literatura) como medio para exponer la importancia de la transdisciplinariedad en la educación superior.

La intención es perfilar ciertas características para llevar a cabo dicha inducción y proponer actividades concretas para su posible desarrollo. Por eso, el cómo de la realización de interrelaciones dialogales e interacciones disciplinares se orienta en términos metodológicos y, en especial, a manera de práctica escritural en el área de interés: la educación superior. En los resultados se esbozan ideas que procuran determinar qué es la problematización de la transdisciplinariedad mediante la relación interdisciplinaria entre el arte y la literatura. También como resultado se ofrece la documentación de una actividad de discusión orientada a ser parte de la materia anteriormente mencionada para evaluar los alcances creativo-investigativos de los estudiantes a partir de esta propuesta. 


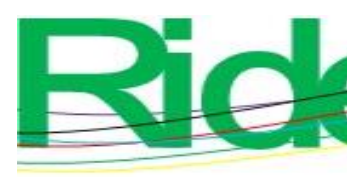

Revista Iberoamericana para la
Investigación y el Desarrollo Educativo
ISSN $2007-7467$

En adelante, y a partir del diálogo con diversos autores en torno a temas relacionados con la inducción al trabajo transdisciplinario, se pretende que estas reflexiones sean concebidas, en el contexto de la educación superior, como una propuesta teórica y exploratoria dirigida a considerar prácticas educativas concretas. Es decir, encaminadas a desarrollar competencias en el sentido de "ser capaces de", lo que aquí se entiende como hacer figura. Desarrollar la capacidad creativo-investigativa para "hacer figura" implica situar históricamente a los partícipes del proceso de aprendizaje. Para realizar esto con apertura a la solidaridad, es necesaria una formación que atienda al trabajo cooperativo ante la problemática de un contexto sociocultural multifacético y problemático. Para ello, se propone (a partir de la Ley General de Educación) un enfoque por competencias cooperativas y se esboza un humanismo racionalista en el ámbito de la práctica educacional. En cuanto a la concepción del cómo de este humanismo, se proponen la hermenéutica y la teoría crítica educacional como metodologías para guiar las interrelaciones dialogales y las interacciones disciplinares.

La hipótesis es que en el ámbito de la educación superior la inducción a la interdisciplinariedad, a partir del arte y la literatura, abre la problematización de la transdisciplinariedad.

\section{De la capacidad creativa para "hacer figura"}

"Hacer figura" se concibe aquí como la meta a conseguir. Para la diferenciación de la capacidad creativa y la capacidad creadora se parte de lo expuesto por Acha (1992) cuando se refiere a un largo proceso creativo que eventualmente conduce a la capacidad creadora: "A este proceso lo denominaremos creativo porque comprende fases previas a la creación” (Acha, 1992, p. 145). Con base en esta diferenciación, se trata de implementar interacciones disciplinares o de colaboración de saberes para el desarrollo de la capacidad creativa orientada a "hacer figura" en la educación superior artística y no artística. Sobre dichas interacciones disciplinares, viene al caso lo indicado por Butor (citado por Vargas, 28 de abril de 2012): "Por eso es tan importante e interesante para mí colaborar con pintores y músicos, porque me dan ideas nuevas, además de que me ayudan a ver y que se vean cosas, a oír y que se escuchen cosas" (p. 4a). 


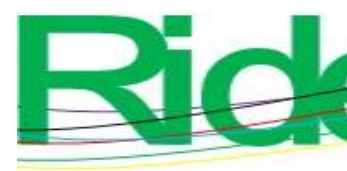

Revista Iberoamericana para la
Investigación y el Desarrollo Educativo
ISSN $2007-7467$

En cuanto al cómo los estudiantes y maestros vean y escuchen cosas, se propone la utilización de imágenes artísticas y textos de prosa o de poesía para su interpretación crítica encaminada al desarrollo de la capacidad creativa. Sobre el cómo establecer relaciones entre el ver y el oír, estas reflexiones sugieren recurrir a la historia de las artes visuales y de la literatura a manera de conexión entre diferentes disciplinas.

En lo concerniente a esta conexión y su pertinencia educativa, se retoma lo expuesto por Butor, quien "sostuvo que entre las palabras y las imágenes existe una relación fuerte, por eso es importante leer y saber cuáles son esos vocablos que están representados en los cuadros" (Palapa, 28 de abril de 2012, p. 4a). Para "hacer figura", y en torno a la imagen, en la historia del arte es rastreable la relación entre el ver y el oír. Por ejemplo, las aportaciones de la Bauhaus y la relación entre el color y el sonido con Kandinsky, o las diversas indagaciones teóricas y prácticas de educación desde la integración de las artes y otros posicionamientos teóricos y experiencias artísticas, como lo expuesto en la obra de Adolfo Sánchez Vázquez, que posibilita el abordaje de problemas como el de la "praxis creadora", concepto que aquí se piensa inherente al fin de "hacer figura": "Es determinante la praxis creadora, ya que esta es justamente la que permite hacer frente a nuevas necesidades, a nuevas situaciones" (Sánchez Vázquez, 1980, p. 303). Desde esta perspectiva, en situaciones estéticas inéditas, a nuestro parecer "hacer figura" implica desarrollar competencias cooperativas interdisciplinares.

\section{Sobre las competencias cooperativas}

"Hacer figura" se interrelaciona aquí con el enfoque por competencias cooperativas en la educación superior que es objeto de las políticas públicas. En el artículo sexto de la Ley General de Educación se indica lo siguiente:

La obligatoriedad de la educación superior corresponde al Estado en los términos dispuestos por la fracción $\mathrm{X}$ del artículo 3. ${ }^{\circ}$ constitucional y las leyes en la materia. Además de impartir educación en los términos establecidos en la Constitución Política de los Estados Unidos Mexicanos, el Estado apoyará la investigación e innovación científica, humanística y tecnológica, y alentará el fortalecimiento y la difusión de la cultura nacional y universal (p. 3). 


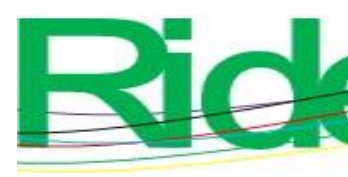

Revista Iberoamericana para la
Investigación y el Desarrollo Educativo
ISSN $2007-7467$

Por su parte, el artículo 16 considera las siguientes disposiciones sobre la educación que imparte el Estado:

Será democrática, considerando a la democracia no solamente como una estructura jurídica y un régimen político, sino como un sistema de vida fundado en el constante mejoramiento económico, social y cultural del pueblo (...). Será humanista, al fomentar el aprecio y respeto por la dignidad de las personas, sustentado en los ideales de fraternidad e igualdad de derechos, promoviendo el mejoramiento de la convivencia humana y evitando cualquier tipo de privilegio de razas, religión, grupos, sexo o de personas (...). Inculcará los conceptos y principios de las ciencias ambientales, el desarrollo sostenible, la prevención y combate a los efectos del cambio climático, la reducción del riesgo de desastres, la biodiversidad, el consumo sostenible y la resiliencia; así como la generación de conciencia y la adquisición de los conocimientos, las competencias, las actitudes y los valores necesarios para forjar un futuro sostenible, como elementos básicos para el desenvolvimiento armónico e integral de la persona y la sociedad (p. 8).

En conformidad con este referente de políticas públicas educativas, en estas reflexiones se subraya el carácter humanista de la educación y lo apuntado sobre "la generación de conciencia y la adquisición de los conocimientos" y competencias.

Sobre el enfoque por competencias sabemos que tiene distintas lecturas, por ejemplo, en términos de origen: "El origen del término competencia también aparece en la antigua Roma, del latín 'competens', que significa 'ser capaz de’” (Arróniz, 2015, párr. 2). Sobre su uso en tiempos recientes, Arróniz señala que se han dado tres enfoques en torno al término competencia: "Tres han sido los enfoques que desde mediados del siglo XX se han dado en relación al término de competencia y estos han sido: conductista, genérico y cognitivo" (Arróniz, 2015, párr. 5).

Las competencias cooperativas con enfoque cognitivo implican atender a aspectos que dan importancia al trabajo colectivo en el proceso de formación de personas críticas y creativas. En el ámbito de la educación superior, el propio Arróniz nos remite a la Ley Orgánica para la Mejora de la Calidad Educativa (LOMCE), en la que se expone la concepción del enfoque por competencias con un sentido crítico: "Es necesario adquirir desde edades tempranas competencias transversales, como el pensamiento crítico, la gestión de la diversidad, la creatividad o la capacidad de comunicar, y actitudes clave como 


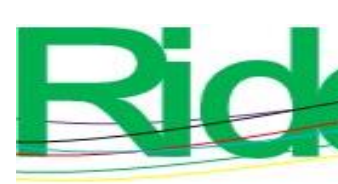

Revista Iberoamericana para la
Investigación y el Desarrollo Educativo
ISSN $2007-7467$

la confianza individual, el entusiasmo, la constancia y la aceptación del cambio" (Arróniz, 2015, párr. 18). La reflexión sobre la interacción disciplinar a partir de la interrelación dialogal tiene puntos de encuentro con las competencias transversales, pues a estas últimas se les interpreta como competencias cooperativas o de interrelación entre los partícipes del proceso de aprendizaje y las tareas cognitivas. En el contexto de nuestro país, Díaz Barriga (2006) se refiere a estas competencias transversales:

En cuanto a las llamadas competencias transversales, varios autores coinciden que en estricto sentido este es el enfoque de la educación por competencias, puesto que en la vida profesional un sujeto no utiliza los conocimientos de una disciplina de manera aislada; los problemas que tiene que resolver reclaman de la conjunción de saberes y habilidades procedentes de diversos campos de conocimiento. De esta manera, los enfoques interpluri-multidisciplinarios constituyen una manera anterior para reconocer el desarrollo de estas competencias (Díaz Barriga, 2006, párr. 54).

En el sentido de la observación de Díaz Barriga, y en torno a la adquisición de los conocimientos y competencias, aquí se considera la interrelación entre el arte y la literatura como afín a la inducción a diálogos humanizadores en cuanto cooperativos. Al respecto, escribe Gadamer (1994): "El hacerse capaz de entrar en diálogo a pesar de todo es (...) la verdadera humanidad del hombre" (p. 209). Con vistas a este "hacerse capaz de entrar en diálogo", se pueden implementar programas educativos con orientación a desarrollar competencias cooperativas humanistas para revertir el desconocimiento de "la problemática conceptual que subyace en este tema". Se pretende contribuir, con perspectiva teórica, a un enfoque que, en atención a la Ley General de Educación vigente, sea favorable para una educación humanista, multidisciplinar y democrática. Un enfoque que considere distintas posibilidades para el desarrollo de capacidades de cooperación conforme a lo que Díaz Barriga llama competencias transversales:

Para Bernard Rey otra forma de analizar las competencias transversales es concebirlas como competencias-elementos. Ello abre la posibilidad de encontrar una transversalidad interior en cada disciplina. La identificación de diversas micro-competencias se convierte en esta perspectiva en un elemento constitutivo de toda operación. "Saber leer - dice - es una competencia que encontramos tanto para resolver un problema de matemáticas, como para 


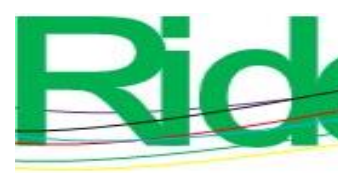

Revista Iberoamericana para la
Investigación y el Desarrollo Educativo
ISSN $2007-7467$

aprender un poema, pero el elemento saber leer no ocupa el mismo lugar en ambas actividades" (Díaz Barriga, 2006, párr. 58).

El trabajo colectivo en torno a las disciplinas de las artes y la literatura es apropiado para que el individuo formado con un enfoque transversal sea capaz de afrontar diversas problemáticas sabiendo leer desde distintas competencias-elementos. En las conclusiones del artículo al que nos hemos referido, escribe Díaz Barriga (2006):

Es probable que el enfoque de competencias pueda mostrar su mayor riqueza si se logra incorporar de manera real en la tarea docente, en la promoción de ambientes de aprendizaje escolares. En este sentido se trataría de pasar de los modelos centrados en la información hacia modelos centrados en desempeños. Los conceptos de movilización de la información, de transferencia de las habilidades hacia situaciones inéditas adquieren una importancia en esta perspectiva (párr. 87).

Para la promoción de ambientes de aprendizaje consecuentes con competencias cooperativas, un humanismo racionalista en el contexto de la educación superior puede promover procesos cognitivo-cooperativos desde la interacción disciplinar. En esta línea, este artículo muestra, en la tabla 1 , los resultados obtenidos en una actividad realizada en el marco de la Maestría en Estudios Interdisciplinarios en Artes y Humanidades de la Universidad Autónoma de Querétaro, en que se promueve el diálogo entre las artes y las humanidades para la generación de problemáticas por parte de los estudiantes.

\section{Racionalidad}

Este análisis descriptivo de ciertas posibilidades de educación superior con fines de inducción a la interdisciplinariedad hurga en un concepto de humanismo racionalista antitético o en oposición a un racionalismo instrumental. En torno al término racionalidad, pensamos en Weber, de quien dice Gadamer (1994) que "en realidad fue el primero en exponer este gran tema" (p. 50). A la racionalidad y a la racionalización se les considera respectivamente con perfil humanista crítico e instrumental. Sobre esto escribe Brum (2010): 


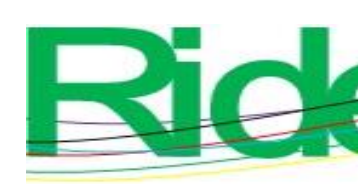

Revista Iberoamericana para la
Investigación y el Desarrollo Educativo
ISSN $2007-7467$

La estructura del actual sistema productivo revela esta racionalización de la actividad tecnológica. Racionalización y racionalidad se sirven de la razón al máximo, pero la racionalidad no se agota en lo instrumental sino que refiere al hombre en su totalidad. La racionalización considera al hombre como instrumento de un modo de producción; en cambio la racionalidad —en el contexto del modo de producción - refiere a una construcción y reconstrucción crítica y progresiva de la actividad total. Es en este sentido que debemos desarrollar la ciencia y la tecnología, pues la racionalidad no puede ser incompatible con la actividad científica. La historia de la racionalidad como algo específicamente humano se afirma en su propia práctica, que presenta un desarrollo complejo y limitado como toda actividad humana (p. 5).

Con propósito comprensivo en torno a la imago y del texto, hacer rizoma implica edificar vías para el encuentro con concepciones disciplinarias que, en su diferencia, aporten a la educación desde un humanismo racionalista afín a la adquisición de conocimientos y competencias cooperativas. Escriben Deleuze y Guattari (2010): “Un rizoma no cesaría de conectar eslabones semióticos, organizaciones de poder, circunstancias relacionadas con las artes, las ciencias, luchas sociales” (p. 18). Estas conexiones rizomáticas están orientadas a la construcción de una intencionalidad moral humanista. Señala Aguilera en torno a Adorno: "La racionalización de la moral (...) niega el impulso, el horror ante los cuerpos torturados y el sentimiento de solidaridad ante lo oprimido, deja abierta la puerta a la violencia, se da la mano con la crueldad que favorece el inmoralismo" (Adorno, 1991, p. 67). En cuanto a una racionalidad moral, y frente a la racionalización de la moral, se considera la diferencia entre las disciplinas artísticas y literarias para ubicar a los partícipes del proceso de aprendizaje con orientación ética y poética. Se trata de realizar, con metodologías específicas, interrelaciones dialogales e interacciones disciplinares para "hacer figura".

\section{El método hermenéutico crítico}

Con el fin de perfilar un diálogo entre las teorías expuestas y apuntar a su mejor comprensión, se refiere aquí a la hermenéutica y a la teoría crítica con el objeto de "hacer figura". Para apoyar la inducción a interacciones disciplinares (arte y literatura), la metodología hermenéutico-crítica, desde su constitución en la teoría crítica educacional, 


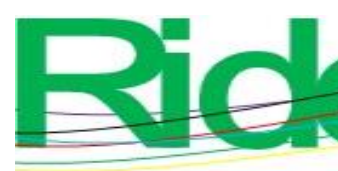

Revista Iberoamericana para la Investigación y el Desarrollo Educativo ISSN $2007-7467$

tiene sentido rizomático en tanto atienda a la multiplicidad de saberes. Esta metodología hace viable la función del lenguaje en un contexto sociohistórico para establecer conexiones entre los aspectos concomitantes a la educación interdisciplinaria como intento de visibilizar la importancia de la transdisciplinariedad. Aspectos orientados al desarrollo de la capacidad creativa para ser capaz de "hacer figura". Para ello, la metodología hermenéutico-crítica y su relación con el lenguaje posibilitan la conexión entre saberes disciplinares en la educación. Desde la experiencia docente y en el ámbito del diseño curricular, se piensa en una hermenéutica crítica a manera de enfoque humanista. Escribe Dussel (2014): “El modelo de las 'ciencias humanas', y aun más las sociales, tiene como componente propio una opción ético-política; es una comprensión 'hermenéutica'” (p. 248).

Una pedagogía con enfoque humanista se orienta a atender problemáticas socioculturales en el ámbito de la educación. En ese contexto, McLaren se pregunta (2005): "Cómo y por qué el conocimiento es construido en la forma en que lo hace, y cómo y por qué algunas construcciones de la realidad son legitimadas y celebradas por la cultura dominante mientras que otras no lo son” (p. 268). Una posibilidad de orientación para crear nuevas conexiones dialogales implica encaminarse en el acceso al conocimiento con "Methodos" o "camino para ir en busca de algo" (Gadamer, 1994, p. 54). La hermenéutica y la teoría crítica pedagógica pueden funcionar a manera de métodos formativos con la interacción del arte y la literatura. Sobre Gadamer, Mardones nos remite a una verdadera conversación:

La conversación es un proceso por el que se busca llegar a un acuerdo. Forma parte de toda verdadera conversación el atender realmente al otro, dejar valer sus puntos de vista y ponerse en su lugar, no en el sentido de que se le quiera entender como individualidad que es, pero sí en el de que se intenta entender lo que dice (Mardones, 1991, p. 291).

Estas verdaderas conversaciones con sentido hermenéutico son un indicativo del cómo realizar interacciones dialogales en las que se expresen problemáticas individuales y colectivas con afán cooperativo y en atención al contexto sociohistórico. Por otra parte, desde la teoría crítica, McLaren (2005) apunta lo siguiente: "El mundo en el que vivimos es construido simbólicamente por la mente merced a la interacción social con los otros y que es profundamente dependiente de la cultura, del contexto, de las costumbres y de la especificidad histórica" (p. 267). Con orientación similar, desde una praxis hermenéutica se hace posible considerar las historias de las personas y de sus contextos comunitarios. 


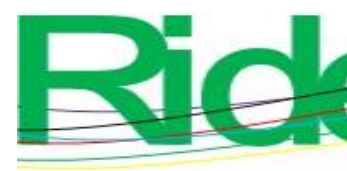

Revista Iberoamericana para la
Investigación y el Desarrollo Educativo
ISSN $2007-7467$

Para el acceso al conocimiento con sentido sociohistórico, se atiende a los intereses cognitivos de los partícipes del proceso a partir de verdaderas conversaciones dadas a la interpretación de sus voces:

El concepto de voz de Giroux se refiere al conjunto de significados multifacéticos y articulados con los cuales los estudiantes y los maestros se enfrentan activamente en diálogo uno con otro. La voz es un concepto pedagógico importante porque alerta a los maestros del hecho de que todo discurso está situado históricamente y mediado culturalmente, y que deriva parte de su significado de la interacción con los demás (McLaren, 2005, p. 325).

Se trata de promover conexiones e interpretaciones desde diversos niveles de realidad a partir de las voces de los partícipes del proceso de aprendizaje.

Sobre la interpretación, escribe Gadamer (1994): "Pertenece al ser humano como tal. Por eso las denominadas 'ciencias del espíritu' se llamaban y se llaman con razón humaniora o humanities. Esto ha perdido claridad con el desarrollo del método y de la ciencia como rasgo esencial de la época modera" (p. 281). En cuanto a la realización de las conexiones dialogales en la educación, estas se pueden acompañar con temáticas humanísticas concretas desde diversas áreas de conocimiento ante un texto, entendido como cualquier "situación humana que posea un contenido simbólico" (Sáenz, s. f., párr. 34).

Desde esta perspectiva, y a partir de las voces de los partícipes en verdaderas conversaciones o en interrelaciones dialogales, se trata de formar en el contexto de la educación superior voces capaces de interpretar y dar sentido al texto desde un humanismo racionalista.

\section{Interrelación dialogal e interacción disciplinar}

En el aula se puede trabajar para "hacer figura" relacionando el pasado con un presente en prospectiva, esto es, con sentido histórico, cambiante. Un trabajo cooperativo entre diálogos disciplinares propicia entre los partícipes del proceso educativo la implementación de conexiones en continuo, esto - y siguiendo a Díaz Barriga - ante "situaciones inéditas" que, en términos sociohistóricos, la teoría crítica considera en continuidad. Esta teoría crítica — según Sáenz (s. f.)— "se construirá a partir de las interpretaciones de los profesores-alumnos; formará parte de los esquemas de los participantes aquella actitud de no dar nada por concluido (carácter dialéctico-negativo del 


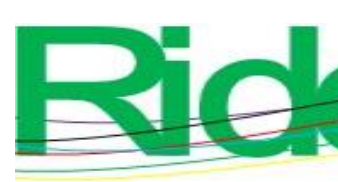

Revista Iberoamericana para la
Investigación y el Desarrollo Educativo
ISSN $2007-7467$

método crítico-ideológico)" (párr. 52). Conforme al objetivo de "hacer figura", se pueden hacer ver y oír en su transformación situaciones varias a partir de las artes y la literatura con las que se trata de "retener solamente (...) lo que incrementa el número de conexiones" (Rajchman, 2004, p. 9).

Entre las artes y las humanidades —o en interacciones disciplinares - el trabajo colectivo puede aportar a la comprensión crítica situada históricamente para la inducción a la interdisciplinariedad con vías a la comprensión del trabajo transdisciplinario, que con Nicolescu (1996) “se interesa en la dinámica que se engendra por la acción simultánea de varios niveles de Realidad" (p. 38). Con la propuesta de hacer figura a partir de interrelaciones dialogales, se pretende atender a posicionamientos éticos y poéticos en torno al trabajo colectivo, incluso, en el diferir en verdaderas conversaciones en torno a diversas problemáticas. A estas interrelaciones dialogales se les piensa orientadas a la implementación de verdaderas conversaciones humanizadoras y racionales: "Un diálogo logrado hace que ya no se pueda recaer en el disenso que lo puso en marcha. La coincidencia que no es ya mi opinión ni la tuya, sino una interpretación común del mundo posibilita la solidaridad moral y social" (Gadamer, 1994, p. 185).

La implementación de las interrelaciones dialogales y de las interacciones disciplinares podría desarrollarse integrando grupos de estudiantes de ciencias y humanidades. Con su coincidencia en espacios educativos compartidos, se buscarían realizar actividades o trabajos que sean propicios para la formación de criterio en torno a temáticas varias, como las de género, de raza y de clase. Temáticas puestas a debate a partir de la lectura (aquí propuesta) de obras artísticas y literarias para el aprendizaje cooperativo:

Cuando los teóricos críticos afirman que el conocimiento está socialmente construido, quieren decir que es producto del acuerdo o consentimiento entre los individuos que viven relaciones sociales particulares (por ejemplo de clase, de raza y de género) y que viven en coyunturas particulares en el tiempo (McLaren, 2005, p. 267).

En ámbitos ajenos a la educación artística o literaria, no se sugiere que se realice arte o se desarrolle la capacidad creadora, sino desarrollar la capacidad creativa y hacer figura en concreto con la práctica de la escritura y su relación con la imagen. Lo anterior se puede efectuar a partir de distintas actividades como la interpretación de imágenes u otras artes para traducirlas en palabras, y viceversa. 


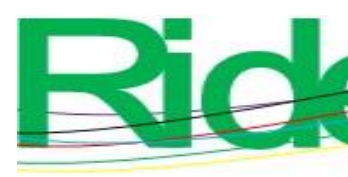

Revista Iberoamericana para la
Investigación y el Desarrollo Educativo
ISSN $2007-7467$

En torno a la problemática del ver y el oír (entre otras posibilidades de percepción como acceso al conocimiento), la interacción entre artes y escrituras implica la conexión dialogal entre estudiantes de distintas áreas profesionales o disciplinarias. Esto con una consciente y compartida posición rizomática, en cuanto "cualquier punto del rizoma puede ser conectado con cualquier otro, y debe serlo" (Deleuze y Guattari, 2010, p. 17).

En relación con el cómo de la implementación de interrelaciones dialogales e interacciones disciplinares, se propone desarrollar una intencionalidad rizomática que se puede implementar entre estudiantes y maestros, y con ello desarrollar competencias cooperativas a través de actividades de comprensión, de interpretación y de la práctica escritural desde distintos programas educativos.

La práctica escritural se puede promover a partir de obras de artes visuales universales, nacionales y locales que son (como indica Butor, citado por Palapa, 28 de abril de 2012) "mosaicos de alegorías y que podemos traducir poco a poco. Existe toda una investigación de la historia del arte para encontrar esas palabras que están bajo las imágenes de las pinturas" (Palapa, 28 de abril de 2012, p. 4a). Con intencionalidad rizomática para con el arte y la literatura se trata de realizar prácticas escriturales para "encontrar las palabras que están bajo las imágenes". Prácticas orientadas a "hacer figura" "a través de la actividad de escribir (...), esa extraña selección en la que ustedes devienen acto" (Deleuze, 2008, pp. 53-54). Esta práctica escritural considera la conexión entre la lectura de imágenes artísticas y de obras literarias, y se realiza a partir de interrelaciones dialogales críticohermenéuticas como las que a continuación se proponen:

- La comprensión de textos literarios cuya lectura semiótica (semántica, sintáctica y pragmática) pueda dialogar con obras de arte en lo general (escénicas, musicales y visuales). En especial, con las disciplinas del dibujo, la pintura, la estampa, la arquitectura, la fotografía, el cine, entre otras.

- La interpretación que exponga por escrito el diálogo existente entre ambas obras.

- Aplicar creativamente (en términos escriturales o artísticos) lo comprendido e interpretado.

Esta propuesta de inducción al trabajo interdisciplinario tiene por objeto plantear un esquema teórico y práctico que acerque a los maestros y estudiantes a la problemática de la transdisciplinariedad. Nicolescu (1996) señala que el prefijo trans se refiere a "lo que está, a la vez, entre las disciplinas, a través de las diferentes disciplinas y más allá de toda 


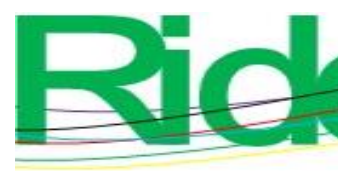

Revista Iberoamericana para la
Investigación y el Desarrollo Educativo
ISSN $2007-7467$

disciplina. Su finalidad es la comprensión del mundo presente, y uno de sus imperativos es la unidad del conocimiento" (p. 37). Así, al trabajo de la interrelación dialogal y la interacción disciplinar se le concibe como un aprendizaje encauzado a la formación de personas propositivas. Educación a favor de la común comprensión e interpretación del mundo con un enfoque de competencias cooperativas y solidarias.

\section{Materiales y métodos}

El presente trabajo de investigación tuvo como sustento un método hermenéutico crítico, pues mediante la comprensión de diversos elementos conceptuales se perfilaron prácticas críticas concretas en torno al estudio de la imago a partir del arte y la literatura. Dichos conceptos se proponen en el contexto de una metodología pertinente para la actividad educativa de inducción a la transdisciplinariedad que se propone.

Por otra parte, se usó material bibliográfico que sustenta el estudio y análisis de los conceptos que se desarrollan en la investigación y de textos literarios y materiales visuales (imágenes principalmente), que fueron la base para el desarrollo de un trabajo interdisciplinario entre las artes plásticas y la literatura, y que se consideraron dentro de la actividad realizada en el curso propedéutico de la maestría en Estudios Interdisciplinarios en Arte y Humanidades. Los resultados se muestran en la tabla 1.

\section{Resultados y discusión}

Con esta práctica educativo-interdisciplinaria se fomenta la capacitación de los estudiantes y maestros para que, capaces de "hacer figura", se sitúen ante un mundo complejo. Dado el carácter exploratorio de estas reflexiones, se da por resultado, también, la necesidad de ampliar la perspectiva teórico-metodológica y, consecuentemente, la investigación sobre la inducción interdisciplinaria, con las artes y la literatura, al trabajo transdisciplinario.

Por último, esta investigación fue la base teórica para la realización de una actividad de inducción a la interdisciplinariedad, llevada a cabo en la clase Fundamentos teóricos de artes visuales que forma parte del curso propedéutico de la maestría en Estudios Interdisciplinarios en Arte y Humanidades, de la Universidad Autónoma de Querétaro. En dicha actividad los estudiantes generaron ideas para un trabajo interdisciplinario entre las artes visuales y las humanidades (u otras disciplinas), partiendo del estudio hermenéutico- 


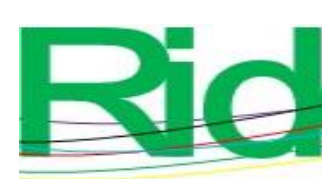

Revista Iberoamericana para la Investigación y el Desarrollo Educativo ISSN 2007 - 7467

\begin{tabular}{|c|c|c|c|}
\hline & $\begin{array}{l}\text { Chile: la rebelión } \\
\text { contra el } \\
\text { neoliberalismo de } \\
\text { Fabio Bucciarelli }\end{array}$ & & $\begin{array}{l}\text { surgido del movimiento } \\
\text { feminista de las últimas } \\
\text { décadas? }\end{array}$ \\
\hline Estudiante 7 & $\begin{array}{l}\text { La tentación de } \\
\text { san Antonio de } \\
\text { Salvador Dalí }\end{array}$ & Teología & $\begin{array}{l}\text { ¿Hay alguna asociación entre } \\
\text { La tentación de san Antonio y } \\
\text { el mito de la torre de Babel? } \\
\text { ¿Cuál es el sentido del castigo } \\
\text { ante la expresión del deseo } \\
\text { individual o colectivo? }\end{array}$ \\
\hline Estudiante 8 & $\begin{array}{l}\text { La anunciación } \\
\text { de Leonardo da } \\
\text { Vinci }\end{array}$ & Teología & $\begin{array}{l}\text { ¿Qué influencia ha tenido la } \\
\text { religión en la producción y } \\
\text { evolución del arte? } \\
\text { ¿El arte como recurso } \\
\text { pedagógico ayuda a los } \\
\text { aprendices a entender mejor la } \\
\text { religión? } \\
\text { ¿Es el arte una extensión } \\
\text { necesaria de sensibilidad para } \\
\text { la religión? }\end{array}$ \\
\hline Estudiante 9 & $\begin{array}{l}\text { La edad madura } \\
\text { (escultura) de } \\
\text { Camille Claudel }\end{array}$ & $\begin{array}{l}\text { Psicología y } \\
\text { sociología }\end{array}$ & $\begin{array}{l}\text { ¿De qué manera y con qué } \\
\text { actitud el personaje del hombre } \\
\text { acepta la transición de la } \\
\text { juventud a la vejez? } \\
\text { ¿Cuál era la postura de la } \\
\text { sociedad de la época de la } \\
\text { artista hacia la mujer como } \\
\text { pareja de un hombre casado? y } \\
\text { ¿qué relación tiene dicha } \\
\text { postura con la de la época } \\
\text { actual? }\end{array}$ \\
\hline $\begin{array}{l}\text { Estudiante } \\
10\end{array}$ & $\begin{array}{l}\text { El eterno } \\
\text { femenino de } \\
\text { Antonio Álvarez } \\
\text { Morán }\end{array}$ & Estudios de género & $\begin{array}{l}\text { ¿Qué es lo femenino? y ¿qué } \\
\text { efecto ha tenido en la sociedad } \\
\text { mexicana el mito del "eterno } \\
\text { femenino"? } \\
\text { ¿Cómo influye el } \\
\text { poscolonialismo y la } \\
\text { interculturalidad en la visión de } \\
\text { la mujer en México? } \\
\text { ¿Cómo se explica la } \\
\text { contradicción social que ocurre } \\
\text { en México en donde } \\
\text { simultáneamente se venera a la } \\
\text { virgen de Guadalupe y se } \\
\text { cometen varios de feminicidios } \\
\text { a diario? }\end{array}$ \\
\hline $\begin{array}{l}\text { Estudiante } \\
11\end{array}$ & $\begin{array}{l}\text { La creación de } \\
\text { Adán de Miguel }\end{array}$ & Psicología & $\begin{array}{l}\text { ¿Cuál es la influencia en el } \\
\text { Renacimiento ante una }\end{array}$ \\
\hline
\end{tabular}




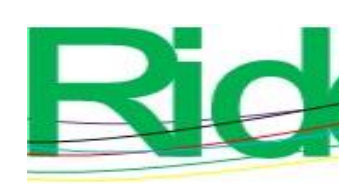

Revista Iberoamericana para la Investigación y el Desarrollo Educativo ISSN 2007 - 7467

\begin{tabular}{|l|l|l|l|}
\hline & Ángel & & $\begin{array}{l}\text { perspectiva artística, } \\
\text { humanística y científica, que } \\
\text { alude a la relación entre la } \\
\text { psicología y el arte? } \\
\text { ¿De qué manera la perspectiva } \\
\text { artística de La creación de } \\
\text { Adán de Miguel Ángel aporta } \\
\text { al debate de la relación del } \\
\text { cuerpo y la mente planteado en } \\
\text { la psicología? }\end{array}$ \\
\hline $\begin{array}{l}\text { Estudiante } \\
12\end{array}$ & $\begin{array}{l}\text { Naturaleza } \\
\text { muerta de Zayda } \\
\text { Ascencio }\end{array}$ & $\begin{array}{l}\text { Historia y estudios } \\
\text { culturales }\end{array}$ & $\begin{array}{l}\text { icuáles son las precisiones, } \\
\text { apropiaciones, } \\
\text { reinterpretaciones y licencias } \\
\text { que la autora ejecutó de } \\
\text { manera consciente o } \\
\text { inconsciente en su obra? } \\
\text { iLa forma caótica de la tela de } \\
\text { fondo no es una contradicción } \\
\text { al sentido medido y ordenado } \\
\text { de los elementos centrales? }\end{array}$ \\
& &
\end{tabular}

Fuente: Elaboración propia

Con verdaderas conversaciones, educadoras y educadores de distintos niveles pueden encaminar la construcción de un humanismo racionalista, crítico y comprensivo.

La discusión sobre la inducción al trabajo transdisciplinario pudiese enfocarse en la pertinencia de las humanidades o humaniora para la definición de políticas públicas educativas desde una racionalidad que atienda a la propia pertinencia del enfoque por competencias cooperativas. Con el arte y la literatura como inducción al trabajo transdisciplinario, aquí se supone que un humanismo racionalista se fortalece con la intencionalidad de teorías y prácticas encaminadas a favor de la cooperación o colaboración que parten de la solidaridad.

Aquí se vislumbran problemáticas concretas a manera de interrogantes que pueden servir para orientar la discusión:

- ¿Es esta propuesta adecuada para una educación comprensiva orientada para "hacer figura" ante un mundo complejo?

- Con perspectiva histórica, ¿la educación con interrelaciones dialogales e interacciones disciplinares es una opción para una educación humanista en los tiempos actuales y en prospectiva? 


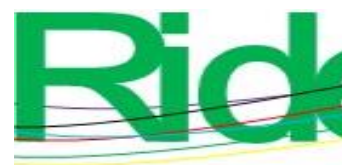

Revista Iberoamericana para la
Investigación y el Desarrollo Educativo
ISSN $2007-7467$

- ¿Existe la posibilidad de diálogos humanizadores entre el racionalismo y la racionalidad?, es decir, ¿es posible permear con humanismo a la techné?

- ¿El reconocimiento de la diferencia disciplinar implica una incidencia práctica para la formación de ciudadanos libres y responsables?

Estas preguntas pudiesen implicar su discusión para "no dar nada por concluido".

\section{Conclusiones}

Ante un mundo complejo, un enfoque crítico y comprensivo sobre la interrelación dialógica y la interacción disciplinar en torno al arte y a la literatura aproxima a los partícipes del proceso de aprendizaje al desarrollo de la capacidad creativa a partir del reconocimiento de la multiplicidad del conocimiento (como se muestra en los resultados expuestos en la tabla 1).

A partir de estas reflexiones, se considera una educación a favor del desarrollo de la capacidad creativa orientada a "hacer figura", intencionalidad que puede aportar, en especial, a la educación superior artística. Esto en conformidad con la Ley General de Educación actual y sus disposiciones a favor de "la generación de conciencia y la adquisición de los conocimientos, las competencias, las actitudes y los valores necesarios para forjar un futuro sostenible, como elementos básicos para el desenvolvimiento armónico e integral de la persona y la sociedad" (p. 9). En conclusión, se considera que las artes y la literatura son disciplinas adecuadas para la concepción y la realización de conexiones entre personas, sus voces, saberes, historias e intereses disciplinares en el contexto de una educación humanizadora.

\section{Futuras líneas de investigación}

El presente trabajo presenta una serie de problemáticas que se pudieran estudiar en

un futuro (ya que su alcance escapa a lo planteado en la presente investigación) como elementos de gran importancia en la educación contemporánea orientada a la inducción al trabajo interdisciplinario.

La primera propuesta de futura línea de investigación compete a la relación entre los conceptos competencias y humanismo en la educación. Así, por ejemplo, se podría plantear el siguiente cuestionamiento: ¿hay una competencia humanista? 


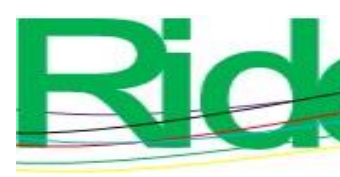

Revista Iberoamericana para la
Investigación y el Desarrollo Educativo
ISSN $2007-7467$

Una segunda interrogante para orientar otra línea de investigación sería esta: ¿cómo inciden en la educación superior los conceptos figura e imagen propios de la actual digitalización del mundo?

\section{Referencias}

Acha, J. (1992). Introducción a la creatividad artística. México: Trillas.

Adorno, T. (1991). Actualidad de la filosofía. España: Paidós.

Arróniz, C. (2015). Origen y evolución de las competencias en educación. EFDeportes Revista Digital, $\quad$ 19(202). Recuperado de https://www.efdeportes.com/efd202/origen-y-evolucion-de-las-competencias-eneducacion.htm

Brum, M. (2010). Reflexiones sobre la racionalidad instrumental. Recuperado de https://docplayer.es/22248978-Reflexiones-sobre-la-racionalidad-instrumentalreflections-on-instrumental-rationality-maria-brum-1-9-ii-2010.html

Deleuze, G. (2008). Pintura. El concepto de diagrama. Buenos Aires: Cactus.

Deleuze, G. y Guattari, F. (2010). Rizoma. España: Pre-textos.

Díaz Barriga, Á. (2006). El enfoque de competencias en la educación. ¿Una alternativa o un disfraz de cambio? Perfiles Educativos, 28(111). Recuperado de http://www.scielo.org.mx/scielo.php?script=sci_arttext\&pid=S018526982006000100002

Dussel, E. (2014). Filosofía de la liberación. México: FCE.

Gadamer, H-G. (1994). Verdad y método. España: Sígueme.

Ley General de Educación. Recuperado de http://www.diputados.gob.mx/LeyesBiblio/pdf/LGE_300919.pdf

Mardones, J. (1991). Filosofía de las ciencias humanas y sociales. Materiales para una fundamentación científica. España: Anthropos.

McLaren, P. (2005). La vida en las escuelas. Una introducción a la pedagogía crítica en los fundamentos de la educación. México: Siglo XXI. Recuperado de https://www.uaeh.edu.mx/profesorado_honorario_visitante/peter_mclaren/presentac iones/LA\%20VIDA\%20EN\%20LAS\%20ESCUELAS.pdf

Nicolescu, B. (1996). La transdisciplinariedad (manifiesto). Ediciones Du Rocher. https://basarab-nicolescu.fr/BOOKS/Manifeste_Espagnol_Mexique.pdf 

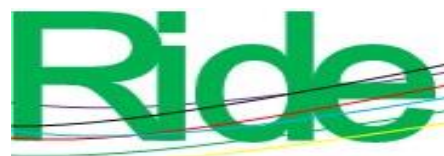

Revista Iberoamericana para la Investigación y el Desarrollo Educativo

ISSN $2007-7467$

Palapa, F. (28 de abril de 2012). Hallar las palabras representadas en una obra de arte es insuficiente, descifremos más datos. La Jornada. Recuperado de https://www.jornada.com.mx/2012/04/28/cultura/a04n2cul

Rajchman, J. (2004). Deleuze: un mapa. Argentina: Nueva Visión.

Sáenz, A. (s. f.). Teoría Crítica y educación. Recuperado de https://educritica.idoneos.com/335283/

Sánchez Vázquez, A. (1980). Filosofía de la praxis. México: Grijalbo.

Vargas, Á. (28 de abril de 2012). Caí en la literatura por caminar entre la pintura y la música: Michel Butor. La Jornada. Recuperado de https://www.jornada.com.mx/2012/04/28/cultura/a04n1cul 